\title{
PEMETAAN POTENSI OBJEK WISATA DENGAN SISTEM INFORMASI GEOGRAFIS DI KECAMATAN NUSA PENIDA KABUPATEN KLUNGKUNG
}

\author{
I Kadek Agus Ariasa ${ }^{1}$, I Wayan Treman ${ }^{2 *}$ \\ Prodi Pendidikan Geografi, Universitas Pendidikan Ganesha, Indonesia
}

\section{A R T I C L EI N F 0}

Article history:

Received 19 Maret 2018

Received in revised form 6 Agustus 2018

Accepted 12 Agustus 2018 Available online 31 Agustus 2018

\section{Kata Kunci:}

pemetaan, potensi wisata dan sistem informasi geografis.

Keywords:

mapping, tourism potential and geographic information systems.

\begin{abstract}
A B S T R A K
Penelitian ini dilaksanakan di Kecamatan Nusa Penida. Tujuan penelitian ini adalah: (1) Mengklasifikasi karakteristik objek wisata di Kecamatan Nusa Penida; (2) Menganalisis tingkat potensi objek wisata di Kecamatan Nusa Penida; (3) Memetakan tingkat potensi objek wisata di Kecamatan Nusa Penida. Objek penelitian ini adalah tentang potensi objek wisata di Kecamatan Nusa Penida. Subjek penelitian ini adalah pengelola wisata dan pelaku usaha di sekitar area wisata. Metode yang digunakan pada penelitian ini adalah metode observasi lapangan, wawancara, dan pencatatan dokumen. Analisis data yang digunakan adalah analisis spasial.

Hasil penelitian ini menunjukan bahwa : (1) Objek wisata yang paling dominan yaitu : wisata bahari, hanya sebagian berupa wisata budaya; (2) Tingkat potensi objek wisata di Kecamatan Nusa Penida terdapat
\end{abstract} variasi, tingkat potensi tinggi, potensi sedang, dan potensi rendah; (3) Persebaran tingkat potensi wisata di 10 Desa di Seluruh Kecamatan Nusa Penida.

\section{A B S T R A C T}

This research was conducted in Nusa Penida Subdistrict. The purpose of this study are: (1) Classifying the characteristics of tourism objects in the District of Nusa Penida; (2) To analyze the potential level of tourism object in Nusa Penida District; (3) Mapping the potential level of tourism object in Nusa Penida District. The method used in in this research is the method of field observation, interview and document recording. Analysis of data used is spatial analysis.

The results of this study show that: (1) The most dominant tourist attraction is: marine tourism, only part of the form of cultural tourism; (2) The level of tourism potential in the subdistrict of Nusa Penida there are variations, high potential level, medium potential, and low potentials; (3) Distribution of tourism potential level in 10 Vilage in Kecamatan Nusa Penida.

\footnotetext{
* Corresponding author.

E-mail addresses:_agusariasa200@gmail.com
} 


\section{Pendahuluan}

Geografi pada dasarnya mempelajari tentang bumi beserta isinya serta hubungan antara keduanya. Semakin meningkat tuntutan kebutuhan manusia, bagian geografi tidak hanya berhenti pada mengetahui dan mempelajari, namun harus dituntut juga mampu memanfaatkan bumi beserta isinya tersebut untuk memenuhi kebutuhan manusia (Sujali, 1989:1). Terkait dengan pemanfaatan bumi beserta isinya untuk memenuhi kebutuhan, maka terdapat suatu kebutuhan yang juga tidak boleh diabaikan oleh manusia yaitu kebutuhan pariwisata.

Pariwisata merupakan sebuah sistem terbuka dan tidak terjadi di dalam ruang hampa. Pariwisata juga berinteraksi dengan lingkungan yang lebih luas, seperti ekonomi, sosial budaya, teknologi, politik, hukum, lingkungan fisik, dan sebagainya.

Bali termasuk salah satu daerah tujuan wisata bagi tamu mancanegara. Ketika Indonesia dilanda krisis moneter Bali tidak surut dalam pengembangan sektor pariwisata. Bali dengan latar kebudayaannya dan aspek lainnya pada mulanya hanya untuk di abadikan demi keagungan masyarakatnya di nikmati oleh masyarakat Bali.

Kabupaten Klungkung memiliki kawasan pariwisata yang terletak di Kecamatan Nusa Penida. Pariwisata di Nusa Penida telah mengalami perkembangan. Hal tersebut dapat dilihat dari data kunjungan wisatawan ke Nusa Penida yang mengalami peningkatan.

Tabel 1. Jumlah Kunjungan Wisatawan di Nusa Penida

\begin{tabular}{rrcc} 
& \multicolumn{2}{c}{ Nusa Penida } & $\begin{array}{c}\text { Peningkatan } \\
\text { No }\end{array}$ \\
\cline { 1 - 3 } Tahun & $\begin{array}{c}\text { Jumlah } \\
\text { Kunjungan } \\
\text { Wisatawan }\end{array}$ & \\
\hline 1 & 2010 & 146.309 & - \\
2 & 2011 & 174.841 & 19,5 \\
3 & 2012 & 176.499 & 20,6 \\
4 & 2013 & 179.143 & 22,4 \\
5 & 2014 & 189.909 & 29,7 \\
\hline 6 & 2015 & 230.754 & 57,7
\end{tabular}

Sumber: Dinas Kebudayaan dan Pariwisata Klungkung Tahun 2016

Dilihat dari data tersebut, kunjungan wisatawan dari tahun 2010-2015 mengalami peningkatan hingga 19,5\% - 57,7\%. Peningkatan tersebut tentu berimplikasi terhadap wilayah Nusa Penida.

Nusa Penida memiliki potensi wisata alam maupun budaya, namun masih ada masyarakat yang belum mengetahui, baik masyarakat dalam maupun masyarakat luar, maka dari itu perlu dengan adanya suatu pemetaan potensi wisata berbasis Sistem Informasi Geografis (SIG) di Nusa Penida.

Sistem Informasi Geografis (SIG) merupakan teknologi yang pada saat ini menjadi alat bantu yang sangat esensial dalam menyimpan, manipulasi menganalisis 
dan menampilkan kembali data spasial dan sumber daya alam yang memegang peranan penting dalam kelangsungan hidup manusia. Aplikasi SIG hampir mencakup semua bidang kehidupan manusia, diantaranya adalah peranan SIG untuk bidang sumber daya alam, perencanaan, telekomunikasi, lingkungan, kesehatan, pertahanan, pariwisata, perpajakan dan militer (Prahasta, 2002: 6-8).

Permasalahan pada penelitian ini (1) Bagaimana karakteristik objek wisata di Kecamatan Nusa Penida, (2) Bagaimana tingkat potensi objek wisata di Kecamatan Nusa Penida, (3) Bagaimana persebaran tingkat potensi objek wisatadi Kecamatan Nusa Penida,

Tujuan dari penelitian (1) Mengklasifikasikan karakteristik objek wisata di Kecamatan Nusa Penida. (2) Menganalisis tingkat potensi objek wisata di Kecamatan Nusa Penida. (3) Memetakan persebaran tingkat potensi objek wisata di Kecamatan Nusa Penida.

\section{Metode}

Penelitian ini di laksanakan di Nusa Penida, Kecamatan Nusa Penida terdiri dari 3 (tiga) kepulauan yaitu pulau Nusa Penida, Pulau Lembongan dan Pulau Ceningan, dan dibagi menjadi 16 Desa. Objek pada penelitian ini adalah seluruh ptensi objek wisata yangada di Kecamatan Nusa Penida, sedangkan yang menjadi subjek penelitian ini adalah mengenai karakteristik, tingkat potensi, dan persebaran potensi objek wisata di Kecamatan Nusa Penida. Penelitian ini menggunakan racangan penelitian deskriptif. Data yang digunakan adalah data primer dan sekunder. Data sekunder bersumber dari Badan Pusat statistik Kabupaten Klungkung. Data primer yang telah dikumpulkan selanjutnya akan dianalisis menggunakan analisis deskriptif kualitatif dan kuantitatif dengan menggunakan pendekatan keruangan. Karakteristik wisata. Tingkat potensi wisatad dan Persebaran tingkat potensi wisata di Kecamatan Nusa Penida.

\section{Hasil dan pembahasan}

Objek pada penelitian ini adalah seluruh ptensi objek wisata yangada di Kecamatan Nusa Penida, sedangkan yang menjadi subjek penelitian ini adalah mengenai karakteristik, tingkat potensi, dan persebaran potensi objek wisata di Kecamatan Nusa Penida.

Karakteristik objek wisara bahari ada 10 yaitu : Pantai Atuh, Pantai Swehan, Pantai Cristal Bay, Pantai Uwoh, Pantai Peguyangan, Pantai Toya Pakeh, Pantai Kelingking, Pantai Sakenan, Pantai Masrum dan Hutan Manggrove. Karakteristi Wisata Alam ada 3 yaitu : Bukit Taletubis, Bukit Molenteng dan Ceningan Clip. Karakteristik wisata budaya ada 3 yaitu : Pura Penataran Ped, Pura Goa Giri Putri dan Pura Palung.

Karakteristik objek wisata di Kecamatan Nusa Penida ada 16 objek wisata secara umum/dominan memiliki karakteristik wisata bahari yaitu 10 objek wisata bahari di bagian pesisir diantaranya Pantai Atuh, Pantai Swehan, Pantai Peguyangan, Pantai Klingking, Pantai Toya Pakeh, Pantai Sakena, Pantai Masrum, Pantai Uwog, Pantai Cristal Bay dan Hutan Manggrove. 


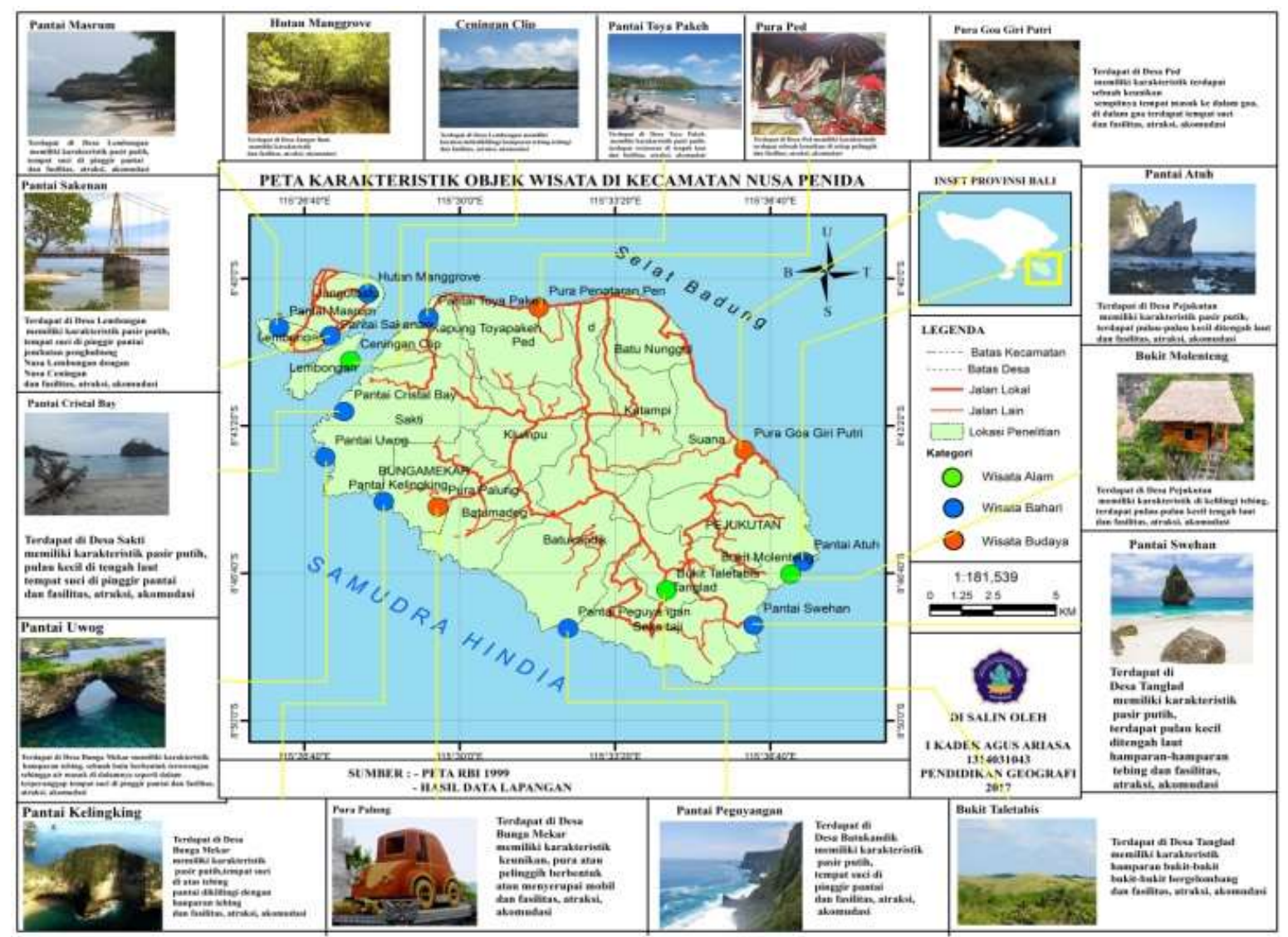

Gambar 1. Peta Karakteristik Objek Wisata

\subsection{Tingkat Potensi Objek Wisata di Kecamatan Nusa Penida}

Tingkat potensi objek wisata di Kecamatan Nusa Penida menghasilkan potensi wisata berdasarkan nilai penskoran yang diperoleh dari pengukuran potensinya seperti skor variabel internal dan skor variabel eksternal, klasifikasi variabel penelitian menggunakan penggabungan perhitungan antara skor maksimum internal jumlah angka minimum dari tiap skor variabel sehingga diperoleh interval dan skor maksimum eksternal dikurangi dengan penggabungan skor minimumnya, sehingga akan diperoleh interval selanjutnya interval tersebut dibagi menjadi 3 (tiga). Sehingga terdapat variasi pada tingkat potensi wisata tinggi, tingkat potensi wisata sedang dan tingkat potensi wisata rendah.

Potensi rendah terdapat di objek wisata Bukit Taletubis, Pantai Peguyangan, Ceningan Clip, Pantai Uwog dan Pantai Swehan. Potensi sedang terdapat di objek wisata Pantai Klingking, Pura Palung, Pantai Atuh, Pantai Cristal Bay dan Bukit Molenteng dan Potensi tinggi terdapat di objek wisata, Pantai Sakenan, Pantai Masrum, Pantai Toya Pakeh, Pura Ped, Pura Goa Giri Putri dan Hutan Manggrove. 


\subsection{Persebaran Tingkat Potensi Objek Wisatadi Kecamatan Nusa Penida}

Persebaran potensi wisata di Kecamatan Nusa Penida sebagian besar berada di daerah pesisir yaitu wisata bahari atau wisata pantai dan tidak tersebar secara merata hanya terdapat pada beberapa tempat, selama ini baru 16 objek wisata yang sudah dikembangkan atau dikelola oleh masyarakat yang daerahnya dekat dengan objek wisata yang ada di Nusa Penida.

Persebaran tingkat potensi objek wisata yang ada di Kecamatan Nusa Penida dibagi tiga kategori yaitu : Tinggi, sedang dan rendah. Kategori tinggi terdapat pada bagian utara Pulau Nusa Penida yaitu, Pantai Masrum, Pantai Sakenan, Hutan Manggrove, Pantai Toya Pakeh, Pura Penataran Ped dan Pura Goa Giri Putri. Faktor penyebab ke- 6 objek tersebut terkategori tinggi adalah memiliki daya tarik utama objek wisata seperti keindahan alam, cirri khas makanan, ketersediaan fasilitaspenginapan dan restourant, kegiatan di lokasi sudah tersedia seperti tempat treckeng dan tempat perkemahan, kondisi fisik bangunan sangat baik seperti atap masih baru, dinding masik kokoh bersih, lantai baru dan terawat, prasarana jalan menuju objek wisata tersedia kondisi baik beraspal baru, jarak dari terminal atau pelabuhan dekat sehingga mudah dijangkau oleh para wisatawan, ketersediaan kebutuhan sosial seperti taman terbuka, fasilitas seni budaya, tempat ibadah.

Kategori sedang terdapat pada objek Pantai Cristal Bay, Pantai Klingking, Pura Palung, Bukit Molenteng dan Pantai Atuh. Faktor penyebab dari ke-5 objek tersebut terkategori sedang adalah tersedia dan beraspal tapi dalam kondisi berlubang-lubang, fasilitas dan akomodasi masih kurang baik. Kategori rendah terdapat pada objek Ceningan Clip, Pantai Uwog, Pantai Peguyangan, Bukit Taletabis dan Pantai Swehan. Faktor penyebab dari ke-5 objek tersebut terkategori rendah adalah kondisi jalan sangat kurang baik seperti tidak beraspal, jauh dari terminal atau pelabuhan terdekat sehingga menguranggi keingginan para wisatawan untuk berkunjung ke objek tersebut selain itu fasilitas tidak memadai seperti penginapan, restoran masih hanya ada beberapa saja. 


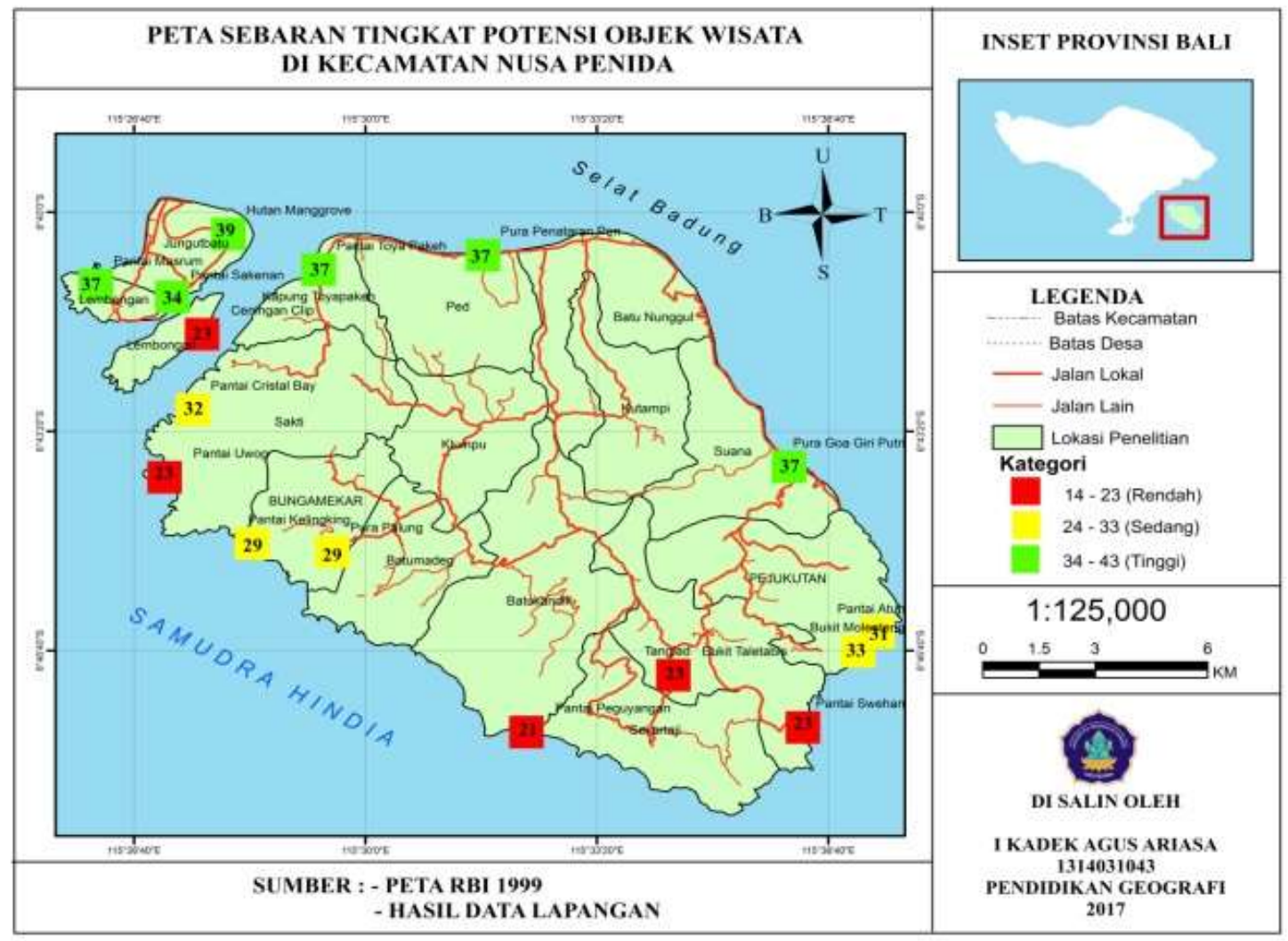

Gambar 2. Peta Persebaran Tingkat Potensi Objek Wisata

\section{Simpulan dan saran}

Karakteristik objek wisata di Kecamatan Nusa Penida Berdasarkan hasil yang di dapat mengenai objek wisata di Kecamatan Nusa Penida ada 16 objek wisata, secara umum/dominan memiliki karakteristik wisata bahari yang berada di bagian daerah pesisir terdapat 10 objek wisata bahari yaitu : Pantai Atuh, Pantai Swehan, Pantai Peguyangan, Pantai Klingking, Pantai Toya Pakeh, Pantai Sakenan, Pantai Masrum, Pantai Uwog, Pantai Cristal Bay dan Hutan Manggrove. Tingkat potensi objek wisata di Kecamatan Nusa Penidavariasi, potensi rendah potensi sedang dan potensi tinggi. Persebaran tingkat potensi objek wisata di Kecamatan Nusa Penida Berdasarkan hasil yang diperoleh pada penyajian data mengenai persebaran tingkat potensi objek wisata yang ada di Kecamatan Nusa Penida dibagi adanya variasi Tinggi, sedang dan rendah. Kategori tinggi terdapat pada bagian utara Pulau Nusa Penida yaitu, Pantai Masrum, Pantai Sakenan, Hutan Manggrove, Pantai Toya Pakeh, Pura Penataran Ped dan Pura Goa Giri Putri. Faktor penyebab dari ke-6 objek tersebut terkategori tinggi adalah jarak dengan pelabuah atau pintu masuk Nusa Penida sangat dekat sehingga mudah di jangkau, prsarana jalan dalam kondisi beraspal baru, tersedia fasilitas penginapan, restouran tersedia di masing-masing objek. Kategori sedang terdapat pada objek Pantai Cristal Bay, Pantai Klingking, Pura Palung, Bukit Molenteng dan Pantai Atuh. Faktor penyebab dari ke-5 objek tersebut adalah kondisi jalan rusak berlubang-lubang, 
fasilitas penginapan, restourant masih jarang ada di setiap objek sehingga wisatawan kesulitan untuk mencari tempat menginap. Kategori rendah terdapat pada objek Ceningan Clip, Pantai Uwog, Pantai Peguyangan, Bukit Taletabis dan Pantai Swehan. Faktor penyebab dari ke-5 objek tersebut adalah kondisi jalan sangat buruk seperti tidak beraspal menuju objek tersebut, jarak dari terminal sangat jauh sehingga wisatawan tidak inggin berkunjung ke objek tersebut dan tidak tersedianya fasilitas penginpan dan restourant.

Peneliti selanjutnya bisa mengadakan penelitian mengenai lokasi yang sama dengan sudut pandang berbeda, namun dengan variabel mengukur perkembangan objek wisata. Penelitian ini dapat dijadikan sebagai bahan masukan dalam perencanaan pembangunan dan penataan ruang potensi wisata di Kecamatan Nusa Penida sehingga bisa menjadi kawasan pariwisata yang berkelanjutan. Penelitian ini dapat dijadikan sebagai informasi mengenai lokasi potensi objek wisata sebagai suatu kawasan yang memiliki nilai kelangkaan tinggi, karena potensi wisata ini sangat penting bagi masyarakatluas, maka dari itu masyarakat Nusa Penida harus menjaga potensi wisata ini dengan baik dan melestarikannya.

\section{Daftar Rujukan}

Aditya, I Putu Wahyu. 2015 Pengaruh Pariwisata Terhadap Kondisi Geografis Di Wilayah Nusa Penida Barat.

Anisah, 2007. Sistem Informasi Geografis Pengertian Dan Aplikasinya

BPS Kabupaten Klungkung, 2012. Klungkung Dalam Angka 2012: BPS Kabupaten Klungkung

Dinas Kebudayaan dan Pariwisata Kabupaten Klungkung, Data Kunjungan Wisatawa periode 2010 - 2015. Dinas Kebudayaan dan Pariwisata Kabupaten Klungkung.

Dinas Pariwisata. 2013. Rencana Induk Pengembangan Pariwisata Kabupaten Klungkung.

Dulbahri,2001. Sistem Informasi Geografis.yogyakarta: UGM

Charles E. Gearing Planning for Tourism Develovment Quantitative Approach. Praeger. Fandeli, Chafid. 2001. Dasar-dasar Manajemen Kepariwisataan Alam. Yogyakarta: Liberti.

Handoko. 2004. Kajian Potensi Wisata Alam Pantai di Wilayah Pesisir Pantai Selatan Kabupaten Kebumen. Tersedia pada: https://www.scribd.com/doc/45022228/AnalisisPotensi-Obyek-Wisata-Alam-Pantai-Di-Kbupaten-Gunung-Kidul-Skripsi-DiajukanUntuk-Memenuhi-Persyaratan-Mencapai-Derajat-s. diakses pada 24 Agustus 2015.

Hastuti. 2005. Analisi Potensi Wisata Alam di Daerah Pesisir Selatan Kabupaten Gunung Kidul. Jurnal Ekonomi Pembangunan 2015. Vol,23,No, 4 (hlm. 32-36)

Leedy, Paul D. 1997. Practical Research: Planningand Design. Sixth Edition. Prectice Hall,Upper Saddle River, New Jersey. Chapter 4: "The Review of the Related 


\section{Literature", hal. 71-91.}

Lucyana, Resti. 2010. Sistem Informasi Geografis Untuk Pemetaan Pariwisata Kabupaten Pesisir Barat Berbasis Web. 